\title{
Research on light weight of thin-walled beam for automobile body
}

\author{
Xiang Chen ${ }^{1,2,}$, Yuquan Zhang ${ }^{2}$, Pei $\mathrm{Jia}^{2}$, Zhaowen $\mathrm{Lv}^{2}$, and Rulin $\mathrm{Ma}^{2}$ \\ ${ }^{1}$ School of Bailie Mechanical and Engineering, Lanzhou City University, Lanzhou China \\ ${ }^{2}$ Gansu Shenlan Motor Vehicle Pollution Prevention and Control Research Institute, Lanzhou China
}

\begin{abstract}
The developing trend of the light-weight car is the using of new light-weight materials and the optimization of the car body structure. The beam construction is the major bearing part of the car body. The thinwalled beam of the light-material plays a significant role in lightening the car' own weight, saving the materials, reducing fuel consumption and air pollution. Firstly, the relationship between the thin-walled beam that is fixed in both points and the attribute of the material can be infered from the stiffness coefficient which used as the quantitative index to estimate materials. Then take the body-in-white produced by domestic car factory as an object of study, and use $\mathrm{Cu}$ or $\mathrm{Al}$ or $\mathrm{Mg}$ as the materials of the thinwalled beam to calculate the bending rigidity and torsional stiffness of thewhole car body by using the FEM simulation conducted in HyperMesh.The results show that under the condition of bending and torsion, the SME value is lower when the lighten materials such as $\mathrm{Al}$ or $\mathrm{Cu}$ are used as the bodywork of the thin-walled beam than steel is. Lighten material can greatly reduce the weight of the vehicle. But it also decreased the bending and torsional stiffness of the bodywork. Therefore, in order to avoid decreasing mechanical properties which caused by adopting lighten materials, we must consider the structural design of the thin-walled beam when adopt material for lightweight.
\end{abstract}

\section{Introduction}

Curb mass has great influence on the economics of Vehicle fuel and emission. According to the statics, as curb weight cut down by $10 \%$, fuel consumption cut down by $6 \%$ $-8 \%$. For the no-load automobile, about $70 \%$ of the fuel is consumed for its weight[1]. As a result, lightweight of automobile plays a very important role in improving fuel economy and reduce emissions. At present, the research of lightweight of automobile focus on the application of new lightweight materials and the optimization of body structure[2]. On the premise of guaranteeing the stiffness and modal, sensitivity was analyzed on the thickness of the body mass by reference 3 . Through the optimization of multi-material structure, vehicle performance is improved, and the body mass is significantly reduced, emphasizing the appropriate materials used in the appropriate parts in reference 4.

\footnotetext{
*Corresponding author: Chenxiang-64@126.com
} 
These studies most start from the body cover, discussing how to minimize the weight in the condition of the parts meeting the requirement of stiffness, strength and other static performance. However, these lightweight research neglected that under the premise of meeting the static parameters of automotive components, the requirements of the body stiffness should also be met, because the body stiffness related to the safety of car driving, handling stability and vibration noise and other properties. Therefore, under the premise of ensuring the overall performance of the vehicle unchanged, reducing the mass of beam and column which is the main vehicle load-bearing unit is one of the ways to reduce curb mass. Right now domestic and foreign research results have not yet released.

Based on the theoretical analysis, this paper establishes the mathematical model of light weight of thin-walled beam. Under the premise of meeting the overall performance requirements of the vehicle, the stiffness is used as the evaluation index of the vehicle body, and the real vehicle body produced by a domestic automobile production plant is used as the research model. The feasibility and effect of the lightweight material of the thin-walled beam are discussed by using finite element numerical simulation software to compare, and analyze the effects of steel, aluminum and magnesium as single thin-walled beams and whole body thin-walled beams on the bending and torsional rigidity of the vehicle.

\section{Theoretical model of light weight of thin-walled beam}

\subsection{The evaluation index of lightweight materials}

In order to evaluate the efficacy of the lightweight for the influence of the stiffness, We use the SME(Stiffness Mass Efficient) to measure. Generally the higher SME value is, the bigger stiffness value is and the better effect of lightening weight is. This is given as

$$
S M E=\frac{k}{m}
$$

Where, $\mathrm{k}$ represent equivalent stiffness of the structure; $\mathrm{m}$ is mass of the structure

\subsection{The SME of thin-walled beam}

\subsubsection{The Assumption for thin-walled beam}

We suppose that the beam structure has equal length, and uniform section along length direction, then the constraint of the beam's ends is fixed hinge bearing according to the connection features of its construction within the bodywork.

\subsubsection{The SME model of thin-walled beam}

If the length of the beam of fixed hinge bearing is $\mathrm{L}$, and under the condition of bending and torsional stiffness[10], if the displacement $\mathrm{d}$ under single force $\mathrm{P}$ and torsion angle $\theta$ under torque $\mathrm{T}$,we can infer that equivalent bending stiffness and equivalent torsional stiffness of the beam are respectively $k_{B}$ and $k_{T}$ from regular equation of force method based on the theory of material mechanics. 


$$
\begin{gathered}
k_{B}=\frac{P}{d}=\frac{3 E I}{\left(1-r_{p}\right)^{3} r_{p}{ }^{3} L^{3}} \\
S M E_{T}=\frac{G I_{P}}{\rho A\left(1-r_{T}\right) r_{T} L^{2}}
\end{gathered}
$$

Where, ${ }^{r_{p}}$,and $r_{T}$ represent position parameters of load on the beam; E represent elastic modulus; G represent shear modulus; $I$ represent inertia moment; ${ }^{P}$ represent polar moment of inertia.

Using Eq.(2) and Eq.(3), Eq.(1) may be written as

$$
\begin{gathered}
S M E_{B}=\frac{P}{m d}=\frac{3 E I}{m\left(1-r_{p}\right)^{3} r_{p}^{3} L^{3}} \\
S M E_{T}=\frac{T}{m \theta}=\frac{G I_{P}}{m\left(1-r_{T}\right) r_{T} L}
\end{gathered}
$$

For our hypothesis, the expression would be as follows:

$$
\begin{gathered}
S M E_{B}=\frac{3 E I}{\rho A\left(1-r_{p}\right)^{3} r_{p}^{3} L^{4}} \\
S M E_{T}=\frac{G I_{P}}{\rho A\left(1-r_{T}\right) r_{T} L^{2}}
\end{gathered}
$$

Where, $\rho$ represent density of material; A represent the area of the beam cross section. E, G and $\rho$ are related to the material properties in equation (4), (5), (6), and(7). So the effect of lightening weight is evaluated.

\section{The finite element numerical analysis of the body-in-white}

Taking example of the real body-in-white model produced by a domestic automobile manufacturer,the bending rigidity and torsional rigidity of the whole car body is calculated based on steel, aluminum and magnesium three different thing-walled beam materials. Observation is made of its light-weight effect through comparison of different SME values using different body materials. The finite element model of the body-in-white is shown as in figure 1 .

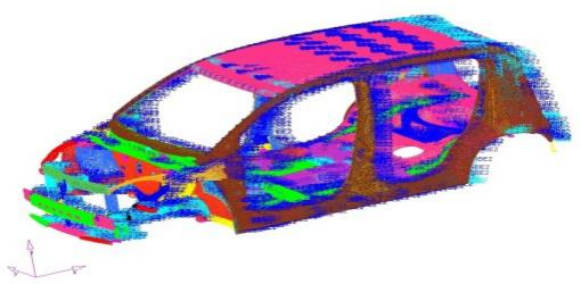


Fig. 1. FEM model of car body-in-white.

Through analysis of the real operational stress environment and the torsional load on the vehicle body, it is worked out that during the bending working condition, the load is vertically exerted in the same direction on the body position which fixed the four seats, as shown in figure 2, while the bending constraint is acted on the position of the front and rear suspension, as shown in figure 3. During the torsional working condition, the load is vertically exerted in the reversed direction on the spring supports of the front suspension, as shown in figure 4, while the torsional restraint is imposed respectively on the spring supports of the real suspension and the front middle position, as shown in figure 5 .

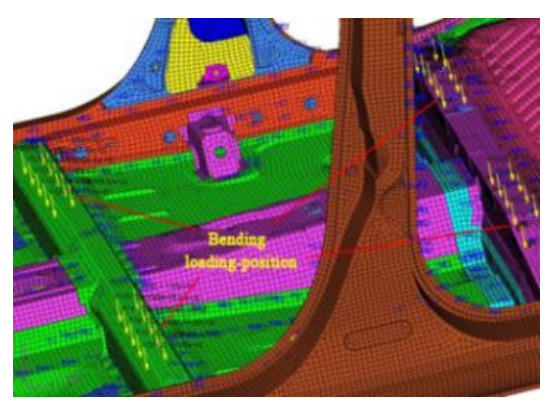

Fig. 2. Bending loading-position.

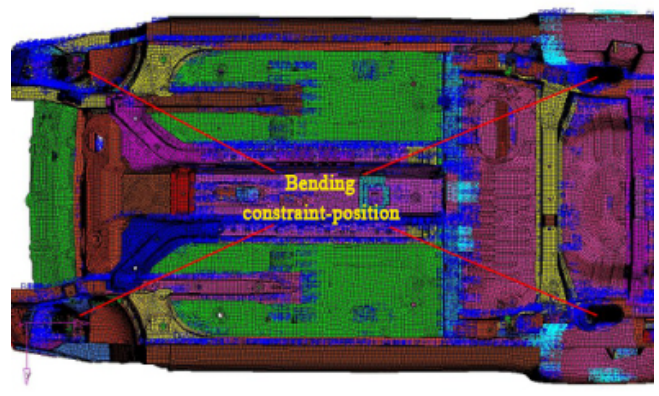

Fig. 3. Bending constraint-position.

Using the OptiStruct solver in HypeMesh to calculate the amount of disformation of the body-in- white with three different materials as its thin-walled beam during the bending and torsional working condition, the body-in-white's bending displacement neghogram is shown in figure 6 and the torsional one is shown in figure 7.

Through analysis of the disformation results, in combination with the loading data, we get the bending SME values and the torsional SME values, as shown in table 1.

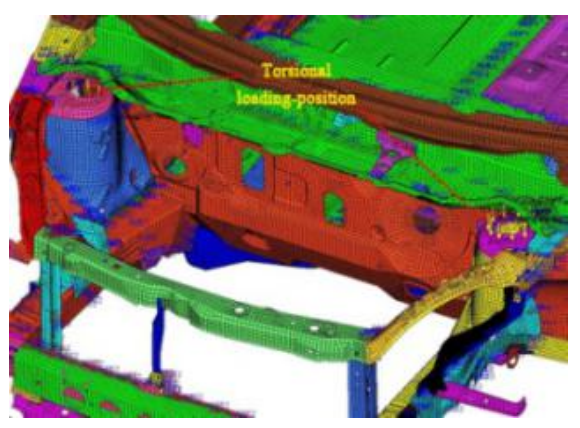

Fig. 4. Torsional loading-position.

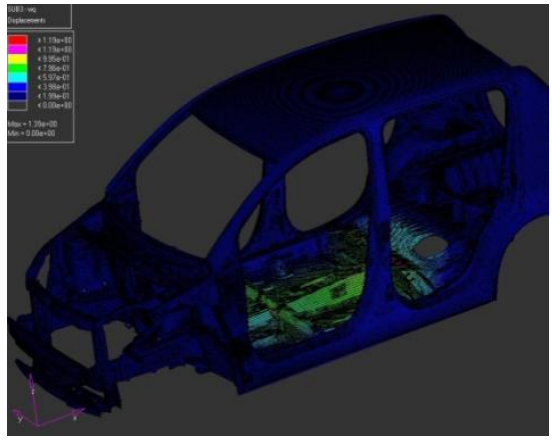

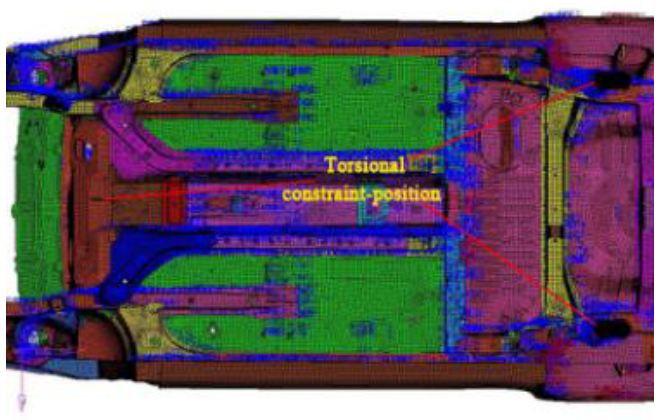

Fig. 5. Torsional constraint-position.

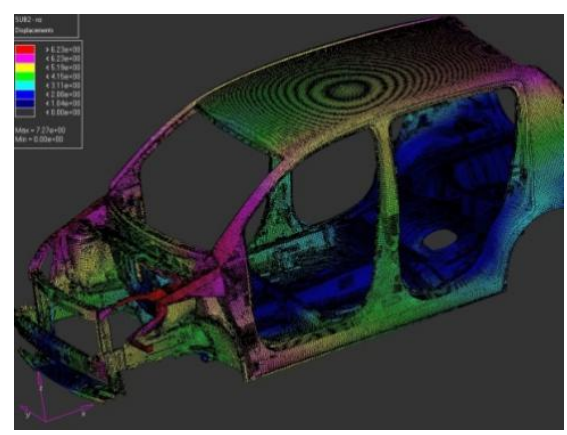


Fig. 6. Bending displacement contour.

Fig. 7. Torsion displacement contour.

Table 1. SME comparison of bending and torsional.

\begin{tabular}{|c|c|c|c|c|c|c|c|}
\hline \multirow[b]{2}{*}{ Materials } & \multirow[b]{2}{*}{$\begin{array}{l}\mathrm{M} \\
(\mathrm{kg})\end{array}$} & \multicolumn{3}{|c|}{ Bending } & \multicolumn{3}{|c|}{ Torsional } \\
\hline & & $\begin{array}{c}\text { Bending } \\
\text { stiffnes } \\
(N / \mathrm{mm})\end{array}$ & $\begin{array}{l}\text { Bending } \\
\text { SME } \\
(N / m m k g)\end{array}$ & $\begin{array}{c}\text { SME } \\
\text { Comparison } \\
(\%)\end{array}$ & $\begin{array}{l}\text { Torsional } \\
\text { stiffness } \\
(N \cdot m / d e g)\end{array}$ & $\begin{array}{c}\text { Torsional } \\
\text { SME } \\
(N \cdot m / d e g \cdot k g)\end{array}$ & $\begin{array}{c}\text { SME } \\
\text { Comparison } \\
(\%)\end{array}$ \\
\hline $\mathrm{Cu}$ & 0.250 & $1.754 \mathrm{E} 4$ & $7.020 \mathrm{E} 4$ & 1 & $5.423 \mathrm{E} 3$ & $2.170 \mathrm{E} 4$ & I \\
\hline Al & 0.085 & 5.892E3 & 6.899E4 & 0.983 & $1.808 \mathrm{E} 3$ & $2.117 \mathrm{E} 4$ & 0.976 \\
\hline Mg & 0.056 & 3.788E3 & $6.728 \mathrm{E} 4$ & 0.958 & $1.162 \mathrm{E} 3$ & $2.064 \mathrm{E} 4$ & 0.951 \\
\hline
\end{tabular}

\section{Conclusion}

No matter whether it is under bending or torsional condition, the SME value of the lightweighted aluminum or magnesium vehicle body is smaller that that of the steel one. Using light- weighted aluminum or magnesium, though the total mass of the vehicle body will be greatly reduced, its corresponding rigidity and other mechanical properties will also be greatly reduced. Therefore, in lightweight design of the vehicle body using the lightweighted materials, consideration must also be made of the effects on its mechanical properties.

Research on highway Safetyperformance analysis and improvement measure in the western mountains-Take the Qidaoliang section of Lanhai highway for example(NO;310822161115)

The key technical research on the auxiliary deceleration lane in Long and Steep Sections(NO:1504FKCA001)

\section{References}

1. Joseph C and Benedyk J C 2000 Light Metals in Automotive Applications J.Light Metal Age vol 10 pp 34-35

2. Merklein M and Geiger M 2002 New Materials and Production Technologies for Innovative Light Weight Constructions J. Journal of Materials Processing Technology pp 532-536

3. Sun Hongtu and Shen Guozhe, Hu Ping 2010 Lightweight Design of an Auto Body Considering its Crash Performance $J$. Mechanical Science and Technology for Aerospace Engineering vol 29 pp 379-382.

4. Li Yongbing, Li Yating and Lou Ming 2012 Lightweighting of Car Body and Its Challenges to Joining Technologies $J$. Journal of Mechanical Engineering vol $48 \mathrm{pp}$ 44-52 